\title{
AP2S1 and GNA11 mutations - not a common cause of familial hypocalciuric hypercalcemia
}

\author{
Silje Hovden ', Lars Rejnmark², Søren A Ladefoged' ${ }^{1}$ and Peter H Nissen' \\ ${ }^{1}$ Departments of Clinical Biochemistry and ${ }^{2}$ Endocrinology and Internal Medicine, Aarhus University Hospital, \\ Aarhus N, Denmark
}

Correspondence

should be addressed

to $\mathrm{P} \mathrm{H}$ Nissen

Email

peteniss@rm.dk

\begin{abstract}
Objective: Familial hypocalciuric hypercalcemia (FHH) type 1 is caused by mutations in the gene encoding the calciumsensing receptor (CASR). Recently, mutations affecting codon 15 in the gene AP2S1 have been shown to cause FHH type 3 in up to $26 \%$ of CASR-negative FHH patients. Similarly, mutations in the gene GNA11 have been shown to cause FHH type 2. We hypothesized that mutations in AP2S1 and GNA11 are causative in Danish patients with suspected $\mathrm{FHH}$ and that these mutations are not found in patients with primary hyperparathyroidism (PHPT), which is the main differential diagnostic disorder.

Design: Cross-sectional study.

Methods: We identified patients with unexplained hyperparathyroid hypercalcemia and a control group of verified PHPT patients through review of 421 patients tested for CASR mutations in the period 2006-2014. DNA sequencing of all amino acid coding exons including intron-exon boundaries in AP2S1 and GNA11 was performed.

Results: In 33 CASR-negative patients with suspected FHH, we found two ( 6\%) with a mutation in AP2S1 (p.Arg15Leu and p.Arg15His). Family screening confirmed the genotype-phenotype correlations. We did not identify any pathogenic mutations in GNA11. No pathogenic mutations were found in the PHPT control group.

Conclusions: We suggest that the best diagnostic approach to hyperparathyroid hypercalcemic patients suspected to have FHH is to screen the CASR and AP2S1 codon 15 for mutations. If the results are negative and there is still suspicion of an inherited condition (i.e. family history), then GNA11 should be examined.
\end{abstract}

\section{Introduction}

Familial hypocalciuric hypercalcemia (FHH) is an autosomal dominant inherited disorder characterized by an elevated level of plasma calcium, relatively high level of parathyroid hormone (PTH), low urinary calcium excretion and generally absence of symptoms $(1,2)$.

Since the 1990s, FHH has been known to be a locus heterogenetic disorder associated with at least three different loci designated FHH type 1, 2 and $3(3,4,5,6)$. FHH1 is caused by heterozygous inactivating mutations in the gene encoding the calcium-sensing receptor (CASR) located on chromosome 3q13.3-q21 (7). The calcium-sensing receptor is a guanine nucleoside-binding protein (G-protein)-coupled receptor (GPCR), which is abundant in the parathyroid glands and in the kidneys, where it is pivotal in the regulation of PTH secretion and renal excretion of calcium. Multiple CASR mutations are associated with $\mathrm{FHH}(8,9,10)$ and consequently genetic analysis of CASR is considered the state-of-theart investigation in FHH (11). However, it has been hypothesized that CASR mutations only explain about $65 \%$ of the suspected cases with FHH (12). The genes responsible for FHH2 and FHH3 have remained unknown until recently, when Nesbit and coworkers identified that mutations in the genes GNA11 and AP2S1, two genes not previously associated to calcium metabolic phenotypes, are responsible for FHH2 and FHH3 respectively $(13,14)$.

Published by Bioscientifica Ltd. 
GNA11 on chromosome $19 \mathrm{q} 3$ encodes subunit $\alpha_{11}$ in the trimeric G-protein and mediates the signaling of GPCRs. Inactivating mutations causes FHH2 and has been found in $0-10 \%$ of patients without mutations in CASR and AP2S1 $(13,15,16)$.

AP2S1 on chromosome 19p13.3 encodes the adaptor protein-2 $\sigma$ subunit, which plays a role in the internalization of membrane proteins, including GPCRs (17). Only mutations affecting codon 15 seem to cause FHH3 and have been identified in 13-26\% of patients with suspected $\mathrm{FHH}$ without CASR mutations $(14,15,18,19)$.

The phenotype of FHH2 resembles that of FHH1 (3), whereas recent studies indicate that FHH3 is characterized by a higher level of both calcium and magnesium and a lower calcium creatinine clearance ratio (CCCR) than FHH1. Furthermore, a relatively high proportion of FHH3 patients report hypercalcemic symptoms, have a lower bone mineral density (BMD) and may suffer from

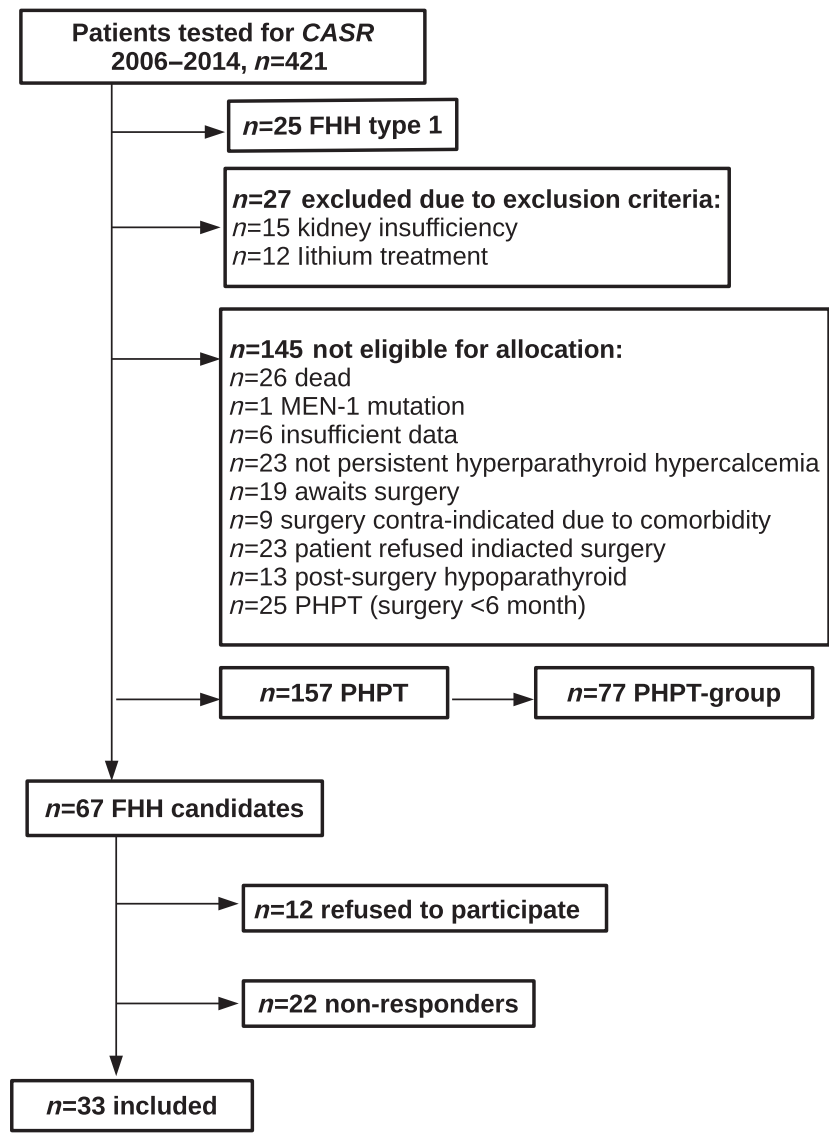

\section{Figure 1}

Flowchart over the review process of patients tested for CASR mutations and the patient inclusion. learning disabilities $(15,19)$. A recent review indicates that symptomatic hypercalcemic FHH3 patients might benefit from treatment with calcimimetics (20).

Due to a similar clinical presentation and overlapping biochemical measures, $\mathrm{FHH}$ is difficult to distinguish from mild primary hyperparathyroidism (PHPT). PHPT often presents with a higher plasma level of PTH and a higher CCCR, whereas FHH patients
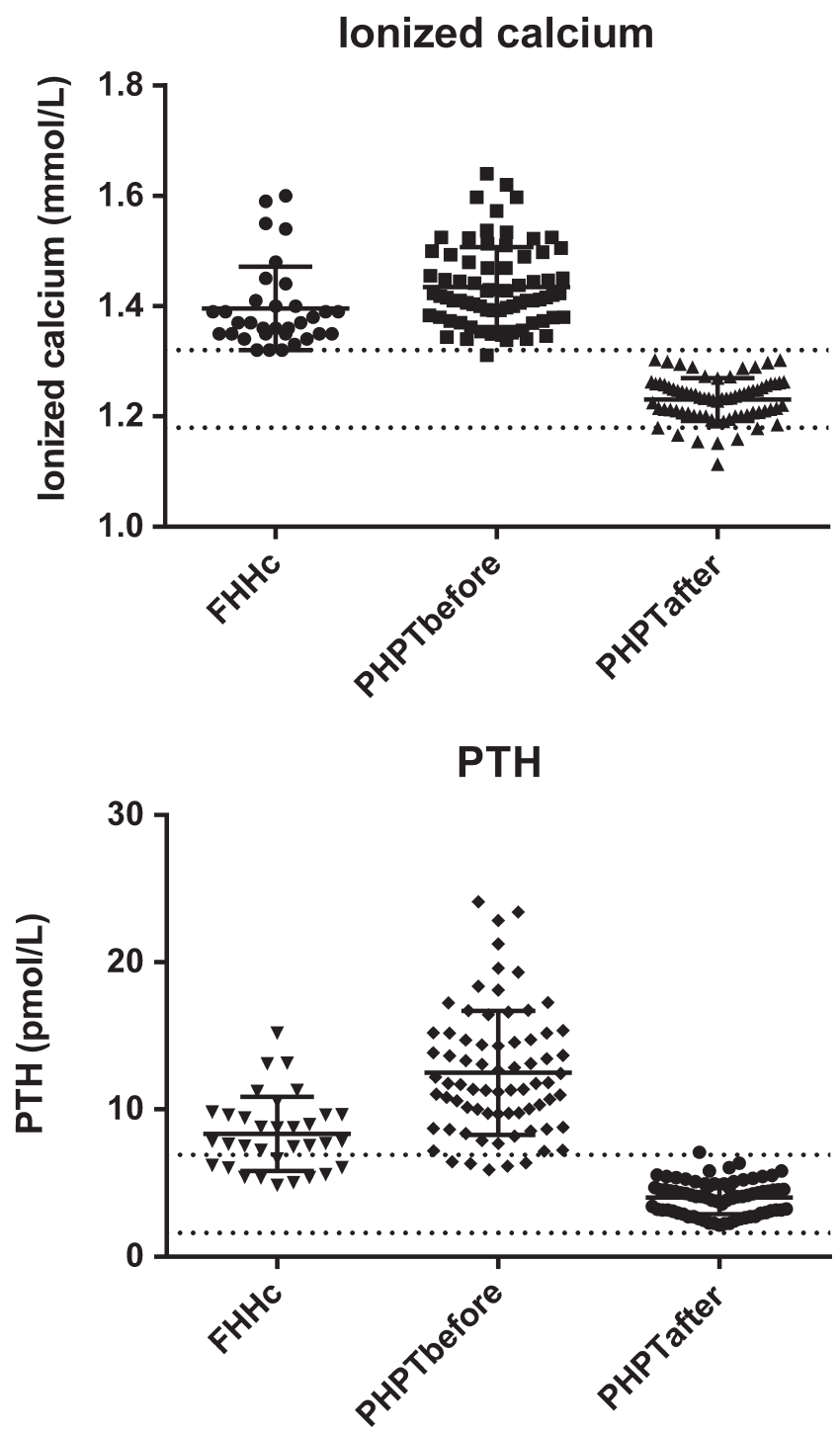

Figure 2

Scatterplot showing the distribution of ionized calcium and parathyroid hormone (PTH) in the familial hypocalciuric hypercalcemia candidate group (FHHc) and in the group of primary hyperparathyroidism before (PHPTbefore) and after (PHPTafter) surgery. The lines indicate the reference intervals (ionized calcium 1.18-1.32 mmol/L and PTH 1.6-6.9 pmol/L). 
have milder PTH elevations and a low $\operatorname{CCCR}(1,21)$. International guidelines recommend screening for $\mathrm{FHH}$ among patients suspected to have PHPT and considers a CCCR $<0.01$ as indicative for FHH (22). However, a cutoff value of CCCR $<0.02$ for referral to genetic testing gives a higher diagnostic accuracy $(11,23)$. As prognosis and treatment differs between the two disorders, it is important to establish the right diagnosis. PHPT can result in severe side effects such as osteoporosis, kidney stones, cardio-vascular disease and depression, whereas the hypercalcemia in FHH caused by CASR mutations, seems not to affect bones, muscles, quality of life or cardiovascular health negatively $(2,24,25,26)$. However, a few cases of chondrocalcinosis and pancreatitis have been reported $(1,21,27)$, and a possible association to developing co-occurring PHPT has been proposed (28). Parathyroidectomy is often curative of PHPT, whereas it does not benefit patients with FHH. We have previously shown that non-curative parathyroidectomies are due to $\mathrm{FHH}$ in $23 \%$ of all cases (9), illustrating the potential consequences of misdiagnosing these two patient groups. Due to the risk of adverse side effects (vocal cord paresis and hypoparathyroidism), parathyroidectomy should be avoided in FHH patients.

To improve the diagnostic approach to $\mathrm{FHH}$ patients, we hypothesized that Danish hyperparathyroid hypercalcemic patients suspected of FHH, without mutations in CASR, would have mutations in either AP2S1 or GNA11 explaining the phenotype. We sequenced the two genes in FHH suspected individuals and to rule out a possible genetic overlap between the two disorders, we analyzed the genes in a control group of PHPT patients. Our results indicate that expanding the genetic screening could be valuable in the diagnostic work-up of selected hypercalcemic patients.

\section{Subjects and methods}

\section{Patient inclusion}

We identified patients ( $>18$ years of age) through review of results from CASR genetic testing performed in our lab on patients with hyperparathyroid hypercalcemia in whom FHH was suspected. The patients were referred from the Department of Endocrinology and Internal Medicine (MEA), Aarhus University Hospital (AUH) from January 2006 to October 2014. The main inclusion criteria for possible FHH 2 or 3 patients were a persistent hypercalcemia (mean ionized calcium level of $>1.32 \mathrm{mmol} / \mathrm{L}$ ) and a concomitant relatively high PTH level (in the upper third of the reference interval or higher equal to plasma PTH $>5.0 \mathrm{pmol} / \mathrm{L}$ ) with no pathogenic variation in CASR. Additionally, a low calcium creatinine clearance ratio $(C C C R<0.02)$, a recurring hypercalcemia after parathyroidectomy and a family history of hypercalcemia were considered. Patients gave written informed consent before participation in the study.

During the review of CASR-tested patients, we identified a control group of PHPT patients. Inclusion depended upon a negative CASR test and successful parathyroidectomy, defined as normocalcemia at least 6 months after surgery. Exclusion criteria for both groups were chronic kidney disease (including previous kidney transplantation) defined as plasma creatinine $>140 \mu \mathrm{mol} / \mathrm{L}$ or treatment with lithium $(29,30)$.

Furthermore, family members of index patients with a presumed pathogenic mutation were invited to participate, and positive responders were screened for the family mutation.

The study was approved by The Health Research Ethics Committee in the Central Denmark Region (no. 1-10-72-174-14) and by the Danish Data Protection Agency (no. 1-16-02-466-14).

Table 1 Biochemical characteristics of the FHH candidate group and the PHPT group. Mean (s.D.).

\begin{tabular}{l}
\hline \\
\hline Calcium ionized $(\mathrm{mmol} / \mathrm{L})$ \\
PTH $(p m o l / L)$ \\
CCCR \\
Magnesium $(\mathrm{mmol} / \mathrm{L})$ \\
Phosphate $(\mathrm{mmol} / \mathrm{L})$ \\
25-OHD $(\mathrm{nmol} / \mathrm{L})$ \\
Alkaline phosphatase (U/L) \\
Creatinine $(\mu \mathrm{mol} / \mathrm{L})$
\end{tabular}

\begin{tabular}{c}
\hline Reference values \\
\hline $1.18-1.32$ \\
$1.6-6.9$ \\
\\
$0.70-1.10$ \\
$0.71-1.53$ \\
$50-160$ \\
$35-105$ \\
$60-105$ \\
\hline
\end{tabular}

\begin{tabular}{c}
\hline FHH candidates $(n=33)$ \\
\hline $1.40(0.08)$ \\
$8.33(2.52)$ \\
$0.011(0.005)^{\mathrm{A}}$ \\
$0.86(0.05)$ \\
$0.91(0.12)$ \\
$79(19)$ \\
$75(22)$ \\
$66(13)$ \\
\hline
\end{tabular}

\begin{tabular}{c}
\hline PHPT $(n=77)$ \\
\hline $1.44(0.07)$ \\
$12.6(4.5)$ \\
$0.014(0.008)^{\mathrm{B}}$ \\
$0.86(0.08)^{\mathrm{B}}$ \\
$0.85(0.13)^{\mathrm{B}}$ \\
$66(21)^{\mathrm{B}}$ \\
$89(29)^{\mathrm{C}}$ \\
$70(15)^{\mathrm{C}}$ \\
\hline
\end{tabular}

\begin{tabular}{c}
\hline $\boldsymbol{P}$-Values \\
\hline$<0.0001$ \\
$<0.0001$ \\
NS \\
NS \\
0.0096 \\
0.006 \\
0.0043 \\
NS
\end{tabular}

$P$ values are calculated with Welch's $t$-test for the difference between the FHH candidates and the PHPT group before surgery. ${ }^{A}$ Data missing from one. ${ }^{B}$ Incomplete data $(n=68-74)$.

25-OHD, 25-hydroxyvitamin D; CCCR, calcium creatinine clearance ratio; FHH, familial hypocalciuric hypercalcemia; PHPT, primary hyperparathyroidism; PTH, parathyroid hormone; NS, not significant. 


\section{Biochemical analyses}

Biochemical analyses of blood and urine were performed in the clinical setting (diagnosis, treatment and/or follow-up) and measurements of ionized calcium, PTH, CCCR, phosphate, magnesium, alkaline phosphatase, 25-hydroxyvitamin D (25OHD) and creatinine were evaluated. We obtained data from 2006 to 2015 from the University Hospital's laboratory information system.

\section{Genetic analysis}

Genomic DNA was isolated from whole blood as described previously (9).

We performed polymerase chain reaction (PCR) of 12 protein-coding exons (five in AP2S1 and seven in GNA11) including the intron-exon boundaries, using the primer sequences from Nesbit et al. (14) for AP2S1 exon 1, 4 and 5. All other primers were designed using Primer3 (31).

The PCR products were purified using the GFX 96 PCR Purification Kit (Illustra, GE Healthcare) and subjected to bidirectional DNA sequencing as described previously (9). One exception was made with GNA11 exon 1, where the sequencing reaction was modified by addition of $5 \%$ DMSO and an initial heat denaturation step $\left(98^{\circ} \mathrm{C}\right.$ for $5 \mathrm{~min}$ ) prior to the addition of sequencing reagents $(32,33)$. Primer sequences, and PCR and sequencing conditions are available on request.

We aligned sequence traces to the reference sequences NM_004069 for AP2S1 and NM_002067 for GNA11 using SeqScape (version 2.7, Life Technologies). All variations from the reference sequences were aligned to the Ensembl (http://www.ensembl.org/Homo_sapiens/Info/Index) (34) and the NCBI SNP databases (http://www.ncbi.nlm. nih.gov/snp/) (35).

\section{Statistical analysis}

The statistical analysis was performed with GraphPad Prism version 6. Data are presented as mean and S.D. Welch's $t$ test was used as the statistical test to determine the differences and a $P$ value $<0.05$ was considered statistically significant.

\section{Results}

We reviewed 421 patients tested for mutations in the CASR (Fig. 1), of whom 25 (5.9\%) had FHH1. We excluded 27 patients (6.4\%) according to the exclusion criteria and excluded 145 (34.4\%) because they were ineligible for

\section{lonized calcium}

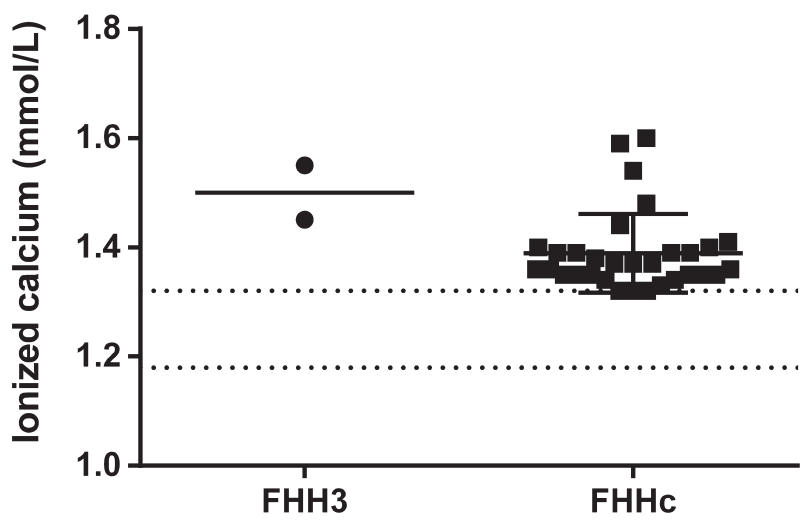

CCCR

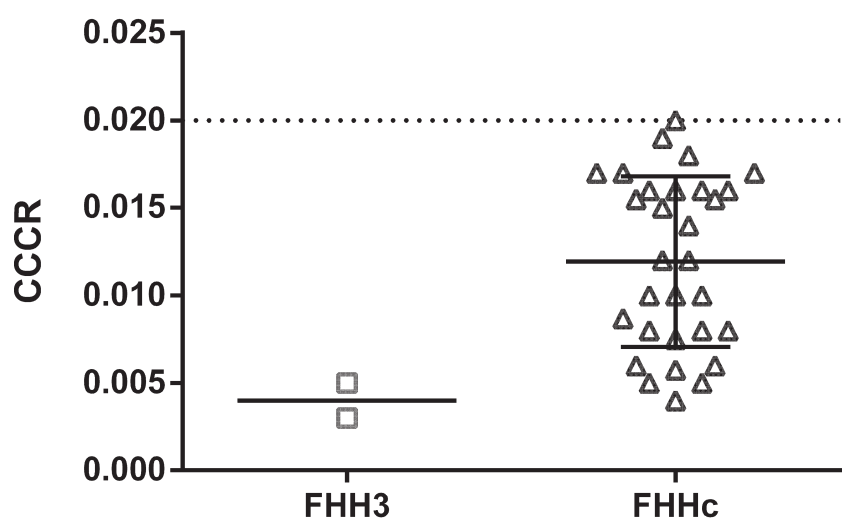

Magnesium

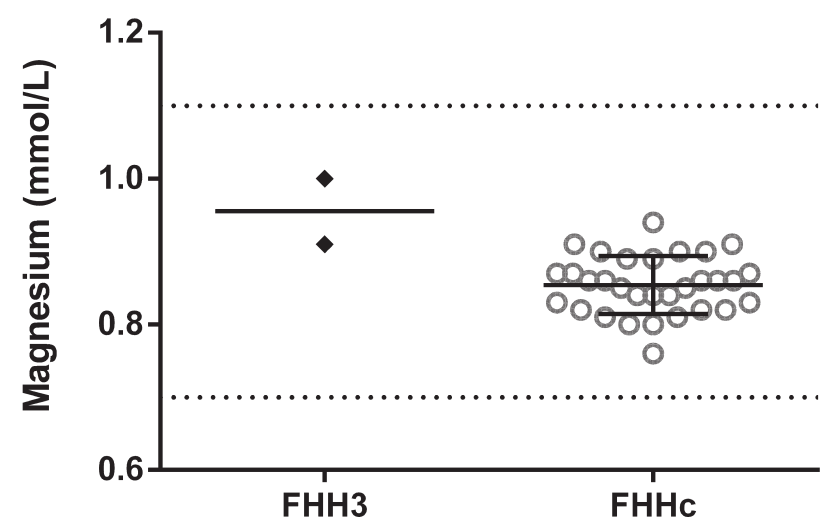

Figure 3

Scatterplot showing the distribution of ionized calcium, calcium creatinine clearance ratio (CCCR) and magnesium in the two patients with familial hypocalciuric hypercalcemia $(\mathrm{FHH})$ type 3 (FHH3) and in the $\mathrm{FHH}$ candidate group (FHHC). The lines indicate the reference intervals (ionized calcium $1.18-1.32 \mathrm{mmol} / \mathrm{L}, \mathrm{CCCR} 0.02$ and magnesium $0.70-1.10 \mathrm{mmol} / \mathrm{L})$. 
Table 2 Biochemical characteristics of the FHH3 patients and the remaining FHH candidate group. Mean (s.D.).

\begin{tabular}{l}
\hline \\
\hline Calcium ionized $(\mathrm{mmol} / \mathrm{L})$ \\
PTH $(p m o l / L)$ \\
CCCR \\
Magnesium $(\mathrm{mmol} / \mathrm{L})$ \\
Phosphate $(\mathrm{mmol} / \mathrm{L})$ \\
25-OHD $(\mathrm{nmol} / \mathrm{L})$ \\
Alkaline phosphatase $(\mathrm{U} / \mathrm{L})$ \\
Creatinine $(\mu \mathrm{mol} / \mathrm{L})$ \\
\hline
\end{tabular}

\begin{tabular}{c}
\hline Reference values \\
\hline $1.18-1.32$ \\
$1.6-6.9$ \\
$0.70-1.10$ \\
$0.71-1.53$ \\
$50-160$ \\
$35-105$ \\
$60-105$ \\
\hline
\end{tabular}

\begin{tabular}{c}
\hline Total without FHH3 $(n=31)$ \\
\hline $1.39(0.07)$ \\
$8.38(2.57)$ \\
$0.012(0.005)^{\mathrm{A}}$ \\
$0.85(0.04)$ \\
$0.93(0.13)$ \\
$80(19)$ \\
$75(22)$ \\
$64(11)$ \\
\hline
\end{tabular}

\begin{tabular}{c}
\hline FHH3 $(n=2)$ \\
\hline 1.5 \\
7.5 \\
0.004 \\
0.95 \\
0.81 \\
67 \\
61 \\
78 \\
\hline
\end{tabular}

AData missing from one.

25-OHD, 25-hydroxyvitamin D; CCCR, calcium-creatinine-clearance-ratio; FHH, familial hypocalciuric hypercalcemia; FHH3, FHH caused by mutations in AP2S1; PHPT, primary hyperparathyroidism; PTH, parathyroid hormone.

allocation. 157 (37.3\%) of the patients had undergone successful parathyroidectomy, and 77 patients from this group were randomly selected to the PHPT control group. The remaining 67 patients (15.9\%) were allocated to the FHH 2 and 3 candidate group.

Of the $67 \mathrm{FHH}$ candidates, 12 patients refused participation for reasons unknown and 22 patients did not respond to the invitation. Consequently, 33 patients with suspected FHH aged 31-88 were included. Of the included patients, $39.4 \%$ had experienced one or more unsuccessful neck explorations. The rest were considered to have FHH due to low CCCR, absence of hypercalcemic symptoms and/or family history. All patients were followed in the out-patient clinic. Figure 2 and Table 1 show the biochemical data from the FHH candidate group and the PHPT group. Patients with verified PHPT had pre-operatively statistically significantly higher levels of ionized calcium, PTH and alkaline phosphatase, and statistically significantly lower levels of phosphate and 25-OHD than the FHH 2 and 3 candidates.

Of the $33 \mathrm{FHH}$ suspected patients, we found a pathogenic mutation in AP2S1 in two unrelated patients: a c.43C $>\mathrm{T}$ substitution resulting in p.Arg15Leu and a c. $44 \mathrm{G}>\mathrm{A}$ substitution resulting in p.Arg15His. No mutations were identified in GNA11 in the FHH suspected group. Figure 3 and Table 2 show the biochemical values of the two FHH3 patients and the rest of the FHH candidate group. There is a tendency of the FHH3 patients having a lower CCCR and a higher level of ionized calcium and magnesium than the rest of the group.

Sequencing of the AP2S1 and GNA11 genes in the control group revealed that the two patient groups had a similar distribution of polymorphisms in GNA11, whereas the control group had a higher allele frequency of normal variants in AP2S1 than the FFH group (data not shown). No FHH-associated mutations were identified in the PHPT group.

\section{Patients with mutation in AP2S1}

The index patient with p.Arg15Leu had a known family history of hypercalcemia (Fig. 4) as her now deceased mother underwent unsuccessful parathyroidectomy resulting in the screening of the family for FHH. Because of the apparent autosomal dominant inheritance, none of the other family members with hypercalcemia were referred to surgery. Two hypercalcemic and two normocalcemic family members were screened for the p.Arg15Leu mutation, confirming the co-segregation of the c.43C $>\mathrm{T}$ genotype

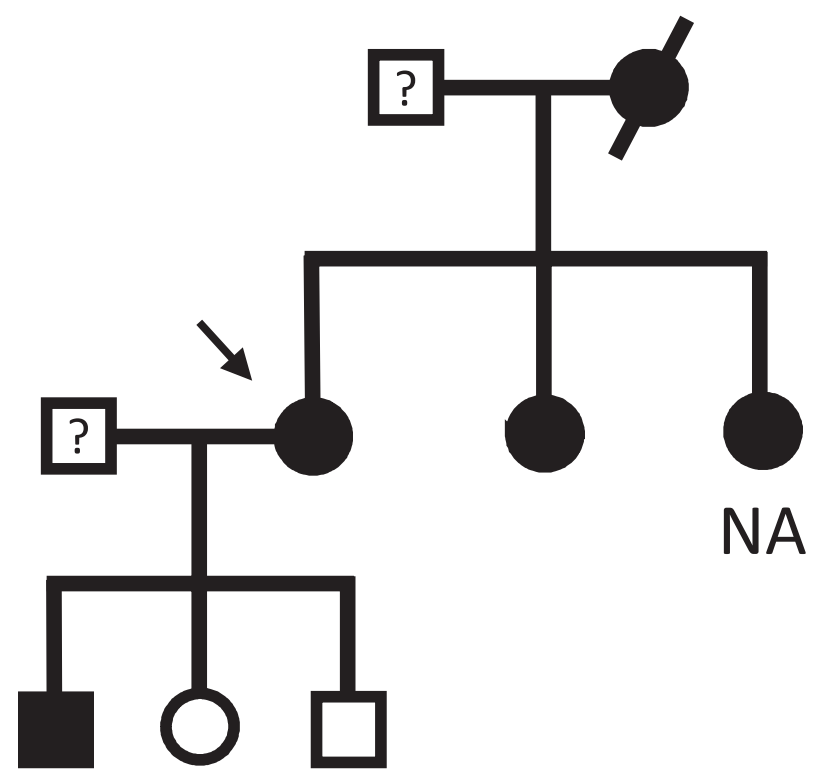

Figure 4

Pedigree of the family with the AP2S1 c.43C > T mutation (p.Arg15Leu). Circles are female and squares are male. Deceased individual is indicated by a slash. Black symbols indicate hypercalcemia, white symbols indicate normocalcemia and ? unknown. The arrow indicates the index patient. NA, not available, but according to family members hypercalcemic. 
Table 3 Biochemical characteristics of mutation positive and negative individuals in family F6.

\begin{tabular}{|c|c|c|c|}
\hline & \multirow[b]{2}{*}{ Reference values } & \multicolumn{2}{|c|}{ Family F6 } \\
\hline & & Mutation positive $(n=3)$ & Mutation negative $(n=2)$ \\
\hline Calcium ionized (mmol/L) & $1.18-1.32$ & 1.53 & 1.29 \\
\hline PTH (pmol/L) & $1.6-6.9$ & 9.2 & 4.3 \\
\hline CCCR & & $0.003^{A}$ & - \\
\hline Magnesium (mmol/L) & $0.70-1.10$ & 0.92 & 0.77 \\
\hline Phosphate (mmol/L) & $0.71-1.53$ & 0.88 & 1.1 \\
\hline 25-OHD (nmol/L) & $50-160$ & 52 & 59 \\
\hline Alkaline phosphatase (U/L) & $35-105$ & 95 & 80 \\
\hline Creatinine $(\mu \mathrm{mol} / \mathrm{L})$ & $60-105$ & 65 & 69 \\
\hline
\end{tabular}

Means are shown. Mutation positive family members have a p.Arg15Leu mutation in AP2S1.

AData missing from two.

25-OHD, 25-hydroxyvitamin D; CCCR, calcium-creatinine-clearance-ratio; PTH, parathyroid hormone.

with hypercalcemia (Table 3). None of the family members had complaints regarding hypercalcemic symptoms. The index patient had a normal BMD ( $T$-score of -0.4 at the lumbar spine, +0.5 at the hip and +0.8 at the forearm). The hypercalcemic son of the index patient suffered from type 1 diabetes, and both he and the sister of the index patient had psychiatric diagnoses/learning disabilities.

As we have previously reported (36), the index patient with the p.Arg15His mutation also had a family history of hypercalcemia believed to be a genetically unverified multiple endocrine neoplasia syndrome (MEN1), but went through multiple parathyroidectomies before the diagnosis of FHH3 was reached (36). Two hypercalcemic and five normocalcemic family members were screened for the p.Arg15His mutation, which resulted in the confirmation of the co-segregation of the c. $44 \mathrm{G}>\mathrm{A}$ genotype with hypercalcemia. Both the index patient and his brother had complaints that could be attributable to hypercalcemia, but had normal BMD except a hip $T$-score of -1.1 and no psychiatric diagnoses (36).

\section{Discussion}

In our cohort of Danish patients suspected of FHH with a normal CASR gene, we found that two patients $(6.1 \%)$ had a heterozygous mutation in AP2S1, whereas no mutations were identified in GNA11. Both mutations have previously been reported to be associated with FHH3 $(14,15,18,19)$ supported by functional studies indicating that cells with mutated AP2S1 were less sensitive to extracellular calcium (14). We also found that the mutations were absent in 77 verified PHPT patients. Some polymorphisms found to be normal variants in AP2S1 were observed with higher allele frequencies in the PHPT group than those in the FHH candidate group. Whether this has any clinical significance needs further investigation.
Our findings are different from the earlier findings, where $13-26 \%$ of CASR-negative patients had AP2S1 mutations and $10 \%$ of CASR- and AP2S1-negative patients had mutations in GNA11 $(13,14,18,19)$. We have no evidence that the prevalence of FHH in Denmark differs from other Caucasian populations and would thus expect similar findings. Stratta el al., on the other hand, did not identify mutations in either AP2S1 or GNA11 in a small Italian population (37). One possible explanation for the lower rate of mutation-positive patients found in our study $(6.1 \%)$ is that the majority of our studied population had a relatively high CCCR between 0.01 and 0.02 (19 of 33 patients). New data suggest that a very low urinary calcium excretion is a characteristic of FHH3 (19), which is supported by the fact that both our genetically verified FHH3 patients had a CCCR $<0.01$ (mean 0.004). If we only look at the group of patients with a CCCR $<0.01$ in our data, we find that $14.3 \%$ had a mutation in AP2S1, thereby resembling the findings in previous studies.

With regard to our negative findings in GNA11, only two studies describe an association of GNA11 and FHH2, reporting three different mutations $(13,16)$. VargasPoussou et al. found no GNA11 mutations in 220 families investigated (15). The sparse published data on FHH2 and our negative findings in 33 investigated hypercalcemic patients, suggest that mutations in GNA11 are a very rare cause of FHH. Gorvin et al. who report a GNA11 mutation estimate that $65 \%$ of $\mathrm{FHH}$ patients will be FHH1, 5\% FHH3 and $<1 \%$ FHH2, but do not explain how they reach these estimates (16).

Previously, the FHH3 phenotype was reported to be characterized by increasing PTH and decreasing phosphate with age causing hypophosphatemic osteomalacia in a large kindred $(14,38)$. This is however not found in other studies $(15,19,39)$. It was recently reported that there was no difference between FHH1 and FHH3 in five unrelated cases 
(18); however, new data based on a total of $70 \mathrm{FHH} 3$ patients including family members of previously described families indicate that the phenotype of FHH3 differs markedly from FHH1 by higher levels of calcium and magnesium and a lower CCCR $(15,19)$. Furthermore, Hannan et al. found that the phenotype differed according to the causative mutation in AP2S1, the p.Arg15Leu mutation causes the highest level of calcium and the lowest CCCR, whereas the p.Arg15His mutation causes the lowest level of calcium and a slightly higher CCCR. This tendency is also seen in our FHH3 families, where the p.Arg15Leu mutation results in a mean ionized calcium level of $1.53 \mathrm{mmol} / \mathrm{L}$ and a CCCR of 0.003 , whereas the p.Arg15His mutation results in a mean ionized calcium level of $1.44 \mathrm{mmol} / \mathrm{L}$ and a CCCR of 0.005 (Table 3 and (36)). However, this specific mutationphenotype correlation is not supported by findings of Vargas-Poussou et al. (15).

Symptoms of hypercalcemia and several other co-morbidities were recently found in FHH3 patients, including low BMD (15), learning disabilities and psychiatric disease $(18,19)$. Our findings do not allow for such conclusions due to the small number of patients, although our findings of possible hypercalcemic symptoms in one of the identified families do support that FHH3 may be associated with more symptoms than FHH1. Furthermore, we found a p.Arg15His mutation in AP2S1 in a patient clinically suspected of having MEN1, but concluded that he was probably an example of a phenocopy (36). However, further studies of co-morbidities are warranted to establish whether these reported diseases are chance findings or actual complications associated with FHH3.

Hannan et al. introduced a calcium-magnesiumCCCR (CMCR) index (albumin adjusted sCa $\times \mathrm{sMg}$ / $(100 \times \mathrm{CCCR}))$ to differentiate FHH1 from FHH3 in patients with suspected FHH. They proposed a diagnostic approach, where the CMCR index is applied to all patients with a CCCR $<0.01$. Patients with a CMCR $>5.0$ should be referred to screening of AP2S1 first, and if negative, CASR and GNA11 should be analyzed, whereas patients with a CMCR $<5.0$ should have all three genes tested. However, they also reported a 30\% overlap between FHH1 and FHH3 when using the CMCR (19). We applied the CMCR post-analytically on our two verified FHH3 index patients and found that both have a CMCR $>5$.0. In contrast, one family member had a CMCR $<5.0$ (4.6), which is in concordance with the $30 \%$ overlap.

One of the strengths of this study is that we have included a control group of 77 patients with confirmed PHPT, which ascertains that the reported mutations are not found in PHPT patients. We are also the first to investigate a Danish population of patients with suspected FHH for mutations in AP2S1 and GNA11, and thus, expand the genetic characterization of a thoroughly investigated clinical cohort.

One limitation to the study is the relatively high proportion of decliners and non-responders that may result in selection bias. The group of non-responders had a higher proportion of men and was slightly younger, but was otherwise not different from the included group (data not shown). Another limitation was the difficulty to reach family members in the FHH3 families who did not have regular contact with the probands, which resulted in a too small group of verified FHH3 patients to make any evaluations of a specific FHH3 phenotype robust.

In conclusion, our study of FHH suspected individuals indicate that GNA11 and AP2S1 are not common causes of hypercalcemia in Denmark. In the light of recent findings, it also indicates that patients with FHH3 caused by an AP2S1 mutation affecting codon 15 have a significant FHH phenotype that may be associated with complications. We propose a diagnostic approach to hypercalcemic patients suspected to have $\mathrm{FHH}$, including sequencing the entire coding region of CASR and screening of the mutation hot-spot in AP2S1. In cases with strong suspicion of FHH despite negative CASR and AP2S1 analyses, genetic analysis of GNA11 should be considered.

Declaration of interest

The authors declare that there is no conflict of interest that could be perceived as prejudicing the impartiality of the research reported.

\section{Funding}

This work was supported by the Department of Clinical Biochemistry, Aarhus University Hospital, 'Fonden til Lægevidenskabens Fremme', 'Grosserer L. F. Foghts Fond' and 'Direktør Jakob Madsen og hustru Olga Madsens Fond'.

\section{Acknowledgements}

The scientific and technical guidance by molecular biologist Pernille Bøttger is warmly appreciated. Phd-student Line Underbjerg is thanked for collaboration.

\section{References}

1 Marx SJ, Attie MF, Levine MA, Spiegel AM, Downs RW \& Lasker RD. The hypocalciuric or benign variant of familial hypercalcemia: clinical and biochemical features in fifteen kindreds. Medicine 1981 60 397-412. (doi:10.1097/00005792-198111000-00002)

2 Jakobsen NFB, Rolighed L, Nissen PH, Mosekilde L \& Rejnmark L. Muscle function and quality of life are not impaired in familial hypocalciuric hypercalcemia: a cross-sectional study on physiological 
effects of inactivating variants in the calcium-sensing receptor gene (CASR). European Journal of Endocrinology 2013169 349-357. (doi:10.1530/EJE-13-0224)

3 Heath H 3rd, Jackson CE, Otterud B \& Leppert MF. Genetic linkage analysis in familial benign (hypocalciuric) hypercalcemia: evidence for locus heterogeneity. American Journal of Human Genetics 199353 193-200.

4 Trump D, Whyte MP, Wooding C, Pang JT, Pearce SHS, Kocher DB \& Thakker RV. Linkage studies in a kindred from Oklahoma, with familial benign (hypocalciuric) hypercalcaemia (FBH) and developmental elevations in serum parathyroid hormone levels, indicate a third locus for FBH. Human Genetics 199596 183-187. (doi:10.1007/BF00207376)

5 Lloyd SE, Pannett AA, Dixon PH, Whyte MP \& Thakker RV. Localization of familial benign hypercalcemia, Oklahoma variant (FBHOk), to chromosome 19q13. American Journal of Human Genetics 199964 189-195. (doi:10.1086/302202)

6 Chou YH, Brown EM, Levi T, Crowe G, Atkinson AB, Arnqvist HJ, Toss G, Fuleihan GE, Seidman JG \& Seidman CE. The gene responsible for familial hypocalciuric hypercalcemia maps to chromosome $3 \mathrm{q}$ in four unrelated families. Nature Genetics 19921 295-300. (doi:10.1038/ ng0792-295)

7 Pollak MR, Brown EM, Chou YH, Hebert SC, Marx SJ, Steinmann B, Levi T, Seidman CE \& Seidman JG. Mutations in the human $\mathrm{Ca}(2+)$ sensing receptor gene cause familial hypocalciuric hypercalcemia and neonatal severe hyperparathyroidism. Cell 199375 1297-1303. (doi:10.1016/0092-8674(93)90617-Y)

8 Hannan FM, Nesbit MA, Zhang C, Cranston T, Curley AJ, Harding B, Fratter C, Rust N, Christie PT, Turner JJO et al. Identification of 70 calcium-sensing receptor mutations in hyper- and hypo-calcaemic patients: evidence for clustering of extracellular domain mutations at calcium-binding sites. Human Molecular Genetics 201221 2768-2778. (doi:10.1093/hmg/dds105)

9 Nissen PH, Christensen SE, Heickendorff L, Brixen K \& Mosekilde L. Molecular genetic analysis of the calcium sensing receptor gene in patients clinically suspected to have familial hypocalciuric hypercalcemia: phenotypic variation and mutation spectrum in a Danish population. Journal of Clinical Endocrinology and Metabolism 200792 4373-4379. (doi:10.1210/jc.2007-0322)

10 Pidasheva S, D'Souza-Li L, Canaff L, Cole DEC \& Hendy GN. CASRdb: calcium-sensing receptor locus-specific database for mutations causing familial (benign) hypocalciuric hypercalcemia, neonatal severe hyperparathyroidism, and autosomal dominant hypocalcemia. Human Mutation 200424 107-111. (doi:10.1002/humu.20067)

11 Christensen SE, Nissen PH, Vestergaard P \& Mosekilde L. Familial hypocalciuric hypercalcaemia: a review. Current Opinion in Endocrinology, Diabetes and Obesity 201118 359-370. (doi:10.1097/ MED.0b013e32834c3c7c)

12 Pearce SHS, Trump D, Wooding C, Besser GM, Chew SL, Grant DB, Heath DA, Hughes IA, Paterson CR, Whyte MP et al. Calcium-sensing receptor mutations in familial benign hyperclacemia and neonatal hyperparathyroidism. Journal of Clinical Investigation 199596 2683-2692. (doi:10.1172/JCI118335)

13 Nesbit MA, Hannan FM, Howles SA, Babinsky VN, Head RA, Cranston T, Rust N, Hobbs MR, Heath H 3rd \& Thakker RV. Mutations affecting G-protein subunit alpha11 in hypercalcemia and hypocalcemia. New England Journal of Medicine 2013368 2476-2486. (doi:10.1056/NEJMoa1300253)

14 Nesbit MA, Hannan FM, Howles SA, Reed AA, Cranston T, Thakker CE, Gregory L, Rimmer AJ, Rust N, Graham U et al. Mutations in AP2S1 cause familial hypocalciuric hypercalcemia type 3. Nature Genetics 201345 93-97. (doi:10.1038/ng.2492)

15 Vargas-Poussou R, Mansour-Hendili L, Baron S, Bertocchio J-P, Travers C, Simian C, Treard C, Baudouin V, Beltran S, Broux F et al. Familial hypocalciuric hypercalcemia types 1 and 3 and primary hyperparathyroidism: similarities and differences. Journal of
Clinical Endocrinology and Metabolism $20161012185-2195$. (doi:10.1210/jc.2015-3442)

16 Gorvin CM, Cranston T, Hannan FM, Rust N, Qureshi A, Nesbit MA $\&$ Thakker RV. G-protein subunit- $\alpha 11$ loss-of-function mutation, Thr54Met, causing familial hypocalciuric hypercalcemia type 2 (FHH2). Journal of Bone and Mineral Research 201631 1200-1206. (doi:10.1002/jbmr.2778)

17 Wagener BM, Marjon NA, Revankar CM \& Prossnitz ER. Adaptor protein-2 interaction with arrestin regulates GPCR recycling and apoptosis. Traffic 200910 1286-1300. (doi:10.1111/j.16000854.2009.00957.x)

18 Hendy GN, Canaff L, Newfield RS, Tripto-Shkolnik L, Wong BYL, Lee BSP \& Cole DEC. Codon Arg15 mutations of the AP2S1 gene: common occurrence in familial hypocalciuric hypercalcemia cases negative for calcium-sensing receptor (CASR) mutations. Journal of Clinical Endocrinology and Metabolism 201499 1311-1315. (doi:10.1210/jc.2014-1120)

19 Hannan FM, Howles SA, Rogers A, Cranston T, Gorvin CM, Babinsky VN Reed AA, Thakker CE, Bockenhauer D, Brown RS et al. Adaptor protein-2 sigma subunit mutations causing familial hypocalciuric hypercalcaemia type 3 (FHH3) demonstrate genotype-phenotype correlations, codon bias and dominant-negative effects. Human Molecular Genetics 201524 5079-5092. (doi:10.1093/hmg/ddv226)

20 Mayr B, Schnabel D, Dörr H-G \& Schöfl C. Genetics in endocrinology: gain and loss of function mutations of the calcium-sensing receptor and associated proteins: current treatment concepts. European Journal of Endocrinology/European Federation of Endocrine Societies 2016174 R189-R208. (doi:10.1530/EJE-15-1028)

21 Law WM \& Heath H. Familial benign hypercalcemia (hypocalciuric hypercalcemia): clinical and pathogenetic studies in 21 families. Annals of Internal Medicine 1985102 511-519. (doi:10.7326/00034819-102-4-511)

22 Bilezikian JP, Brandi ML, Eastell R, Silverberg SJ, Udelsman R, Marcocci C \& Potts JT. Guidelines for the management of asymptomatic primary hyperparathyroidism: summary statement from the fourth international workshop. Journal of Clinical Endocrinology and Metabolism 201499 3561-3569. (doi:10.1210/jc.2014-1413)

23 Christensen SE, Nissen PH, Vestergaard P, Heickendorff L, Brixen K \& Mosekilde L. Discriminative power of three indices of renal calcium excretion for the distinction between familial hypocalciuric hypercalcaemia and primary hyperparathyroidism: a follow-up study on methods. Clinical Endocrinology 200869 713-720. (doi:10.1111/ j.1365-2265.2008.03259.x)

24 Christensen SE, Nissen PH, Vestergaard P, Heickendorff L, Rejnmark L, Brixen K \& Mosekilde L. Skeletal consequences of familial hypocalciuric hypercalcaemia vs primary hyperparathyroidism. Clinical Endocrinology 200971 798-807. (doi:10.1111/j.13652265.2009.03557.x)

25 Wolf P, Krššák M, Winhofer Y, Anderwald C-H, Zwettler E, Just Kukurová I, Gessl A, Trattnig S, Luger A, Baumgartner-Parzer S et al. Cardiometabolic phenotyping of patients with familial hypocalcuric hypercalcemia. Journal of Clinical Endocrinology and Metabolism 2014 99 E1721-E1726. (doi:10.1210/jc.2014-1541)

26 Jakobsen NFB, Laugesen E, Rolighed L, Nissen PH, Poulsen PL, Pedersen EB, Mosekilde L \& Rejnmark L. The cardiovascular system in familial hypocalciuric hypercalcemia: a cross-sectional study on physiological effects of inactivating variants in the calcium-sensing receptor gene. European Journal of Endocrinology 2016175 299-309. (doi:10.1530/EJE-16-0369)

27 Pearce SH, Wooding C, Davies M, Tollefsen SE, Whyte MP \& Thakker RV. Calcium-sensing receptor mutations in familial hypocalciuric hypercalcaemia with recurrent pancreatitis. Clinical endocrinology 199645 675-680. (doi:10.1046/j.13652265.1996.750891.x)

28 Eldeiry LS, Ruan DT, Brown EM, Gaglia JL \& Garber JR. Primary hyperparathyroidism and familial hypocalciuric 
hypercalcemia: relationships and clinical implications. Endocrine Practice 201218 412-417. (doi:10.4158/EP11272.RA)

29 Broome JT \& Solorzano CC. Lithium use and primary hyperparathyroidism. Endocrine Practice 201117 (Supplement 1) 31-35. (doi:10.4158/EP10273.RA)

30 Martínez-Castelao A, Górriz-Teruel JL, Bover-Sanjuán J, Segura-de la Morena J, Cebollada J, Escalada J, Esmatjes E, Fácila L, Gamarra J, Gràcia S et al. Consensus document for the detection and management of chronic kidney disease. Nefrologia 201434 243-262. (doi:10.3265/Nefrologia.pre2014.Feb.12455)

31 Untergasser A, Cutcutache I, Koressaar T, Ye J, Faircloth BC, Remm M \& Rozen SG. Primer3-new capabilities and interfaces. Nucleic Acids Research 201240 1-12. (doi:10.1093/nar/gkr648)

32 Kieleczawa J. Fundamentals of sequencing of difficult templates - an overview. Journal of Biomulecular Techniques 200617 207-217.

33 Choi JS, Kim JS, Joe CO, Kim S, Ha KS \& Park YM. Improved cycle sequencing of GC-rich DNA template. Experimental and Molecular Medicine 199931 20-24. (doi:10.1038/emm.1999.3)

34 Flicek P, Amode MR, Barrell D, Beal K, Billis K, Brent S, Carvalho-Silva D, Clapham P, Coates G, Fitzgerald S et al. Ensembl 2014. Nucleic Acids Research 201442 749-755. (doi:10.1093/nar/ gkt1196)

35 Sherry ST, Ward MH, Kholodov M, Baker J, Phan L, Smigielski EM \& Sirotkin K. dbSNP: the NCBI database of genetic variation. Nucleic Acids Research 200129 308-311. (doi:10.1093/ nar/29.1.308)

36 Hovden S, Jespersen ML, Nissen PH, Poulsen PL, Rolighed L, Ladefoged SA \& Rejnmark L. Multiple endocrine neoplasia phenocopy revealed as a co-occurring neuroendocrine tumor and familial hypocalciuric hypercalcemia type 3. Clinical Case Reports 20164 922-927. (doi:10.1002/ccr3.657)

37 Stratta P, Merlotti G, Musetti C, Quaglia M, Pagani A, Izzo C, Radin E, Airoldi A, Baorda F, Palladino T et al. Calcium-sensing-related gene mutations in hypercalcaemic hypocalciuric patients as differential diagnosis from primary hyperparathyroidism: detection of two novel inactivating mutations in an Italian population. Nephrology, Dialysis, Transplantation 201429 1902-1909. (doi:10.1093/ndt/gfu065)

38 McMurtry CT, Schranck FW, Walkenhorst DA, Murphy WA, Kocher DB, Teitelbaum SL, Rupich RC \& Whyte MP. Significant developmental elevation in serum parathyroid hormone levels in a large kindred with familial benign (hypocalciuric) hypercalcemia. Pediatric Nephrology 19937 378. (doi:10.1007/BF00857543)

39 Nesbit MA, Hannan FM, Graham U, Whyte MP, Morrison PJ, Hunter SJ \& Thakker RV. Identification of a second kindred with familial hypocalciuric hypercalcemia type 3 (FHH3) narrows localization to a $<3.5$ megabase pair region on chromosome $19 \mathrm{q} 13.3$. Journal of Clinical Endocrinology and Metabolism 201095 1947-1954. (doi:10.1210/jc.2009-2152)

Received 7 October 2016

Revised version received 10 November 2016

Accepted 15 November 2016 